\title{
A Rare Presentation of Multi-Organ Embolism in a Multifactorial Hypercoagulable State: Case Report
}

\author{
Uma Apresentação Rara de Embolia Multiorgânica num \\ Estado de Hipercoagulabilidade Multifatorial: Caso \\ Clínico
}

\begin{abstract}
Eva BRYSCH $\triangle^{1}$, Sara SALGADO ${ }^{1}$, António Carvalheira SANTOS ${ }^{1}$, Cristina BÁRBARA ${ }^{1}$
Acta Med Port 2021 Jun;34(6):460-463 - https://doi.org/10.20344/amp.12856

ABSTRACT

Paradoxical embolism is an uncommon phenomenon, accounting for only $2 \%$ of all cases of systemic arterial embolism. This condition suggests the presence of a patent foramen ovale, present in $20 \%-25 \%$ of the adult population. The authors report the case of a 63-year-old male patient with a history of lung adenocarcinoma and hereditary thrombophilia admitted to hospital with acute onset of dyspnea, diplopia, confusion and decreased motor strength of the right limbs. Cranial computed tomography scan showed acute ischemic injury in the left posterior cerebral artery and computed tomography pulmonary angiography revealed bilateral pulmonary thromboembolism. A transesophageal echocardiogram confirmed the presence of patent foramen ovale. The patient was treated with anticoagulant therapy with progressive clinical improvement. Due to a high risk of recurrent thromboembolic episodes, the percutaneous closure of patent foramen ovale was performed and anticoagulant therapy was maintained indefinitely.
\end{abstract}

Keywords: Foramen Ovale, Patent; Lung Neoplasms; Paradoxical Embolism; Thrombophilia

\section{RESUMO}

A embolização paradoxal é um fenómeno incomum, correspondendo apenas a $2 \%$ de todos os casos de embolia sistémica arterial. Esta condição sugere a presença de foramen ovale patente, presente em $20 \%$ - $25 \%$ da população adulta. Os autores relatam um caso de um homem de 63 anos, com os diagnósticos prévios de adenocarcinoma do pulmão e trombofilia hereditária, admitido no hospital com quadro agudo de dispneia, diplopia, confusão e diminuição da força dos membros à direita. A tomografia computorizada crânio-encefálica mostrou uma lesão isquémica cerebral na região da artéria cerebral posterior esquerda e a angiotomografia computorizada torácica revelou tromboembolismo pulmonar bilateral. O ecocardiograma transesofágico confirmou a presença de foramen ovale patente. O doente foi tratado com terapêutica anticoagulante com melhoria clínica progressiva. Devido ao elevado risco de recorrência de eventos tromboembólicos, o doente foi submetido a encerramento percutâneo do foramen ovale patente e a anticoagulação foi mantida por tempo indeterminado.

Palavras-chave: Embolia Paradoxal; Foramen Ovale Patente; Neoplasias do Pulmão; Trombofilia

\section{INTRODUCTION}

Paradoxical embolism is an uncommon phenomenon, accounting for only $2 \%$ of all cases of systemic arterial embolism. This condition suggests the presence of a patent foramen ovale (PFO), present in $20 \%-25 \%$ of the adult population. PFO is usually asymptomatic, but when associated with states of hypercoagulability the risk of systemic embolization is significant. ${ }^{1,2}$ Hereditary thrombophilia and other states of hypercoagulability, as those related to neoplastic diseases, increase the risk of thromboembolic events. ${ }^{3,4}$ Embolic phenomenon occur more frequently in the pulmonary circulation but in the presence of a PFO, with a right to left shunt, cryptogenic strokes may occur. Ischemic stroke causes significant morbidity and mortality and the direct causal relationship between PFO and hypercoagulability states is sometimes difficult to establish. However, this relationship may account for a proportion of cryptogenic stroke cases and should always be investigated. ${ }^{2,5}$

\section{CASE REPORT}

We report a case of a 63-year-old male patient who pre- sented to the emergency department with acute onset of dyspnea, mental confusion, diplopia and decreased muscle strength of the right limbs. The patient was a former smoker and his medical history included factor $V$ Leiden thrombophilia, identified in the context of screening due to family history of recurrent thrombosis. The patient also had a recent diagnosis of lung adenocarcinoma, stage IA2 with microvascular invasion ( $\mathrm{pT} 1 \mathrm{bNOMO}$ of the TNM classification - $8^{\text {th }}$ edition), underwent left upper lobectomy five months prior to admission and completed the last cycle of adjuvant chemotherapy (cisplatin-vinorelbine regimen) six days before admission.

Physical examination revealed tachypnea (26 breaths per minute) tachycardia (heart rate of 120 beats per minute), blood pressure 126/76 $\mathrm{mmHg}$ and an oxygen saturation of $91 \%$ with $\mathrm{FiO}_{2} 44 \%$ of oxygen supplementation $\left(\mathrm{PaO}_{2} / \mathrm{FiO}_{2}\right.$ ratio $\left.=114\right)$. No abnormalities in thoracic, abdominal, and limb examination were found. Neurologically, there was a right homonymous hemianopsia, central right facial palsy, alexia, pain and decrease of proprioceptive

1. Department of Pulmonology. Hospital Pulido Valente. Centro Hospitalar Universitário Lisboa Norte. Lisboa. Portugal.

$\square$ Autor correspondente: Eva Brysch. evabrysch@gmail.com

Recebido: 22 de setembro de 2019 - Aceite: 27 de novembro de 2019 - Online issue published: 01 de junho de 2021

Copyright @ Ordem dos Médicos 2021 
sensitivity, hemiparesis with sensory ataxia of both the upper and lower right limbs and abnormal right plantar reflex.

The 12-lead electrocardiogram revealed a S1Q3T3 pattern. Cranial computed tomography (CT) scan showed a left temporo-occipital hypodensity, without mass effect, suggestive of acute ischemic injury in the territory of the left posterior cerebral artery (Fig. 1). The CT pulmonary angiography (Fig. 2) reveled an endoluminal repletion defect in the distal left pulmonary artery, intermediate artery and bilateral lobular branches, with extension to some segmental and sub segmental branches, compatible with pulmonary thromboembolism. Doppler ultrasound of lower extremities revealed thrombosis in the right posterior tibial vein. Transthoracic echocardiography performed at the bedside (without Doppler) demonstrated dilated right heart cavities with a $19 \mathrm{~mm}$ tricuspid annular plane systolic excursion (TAPSE). The
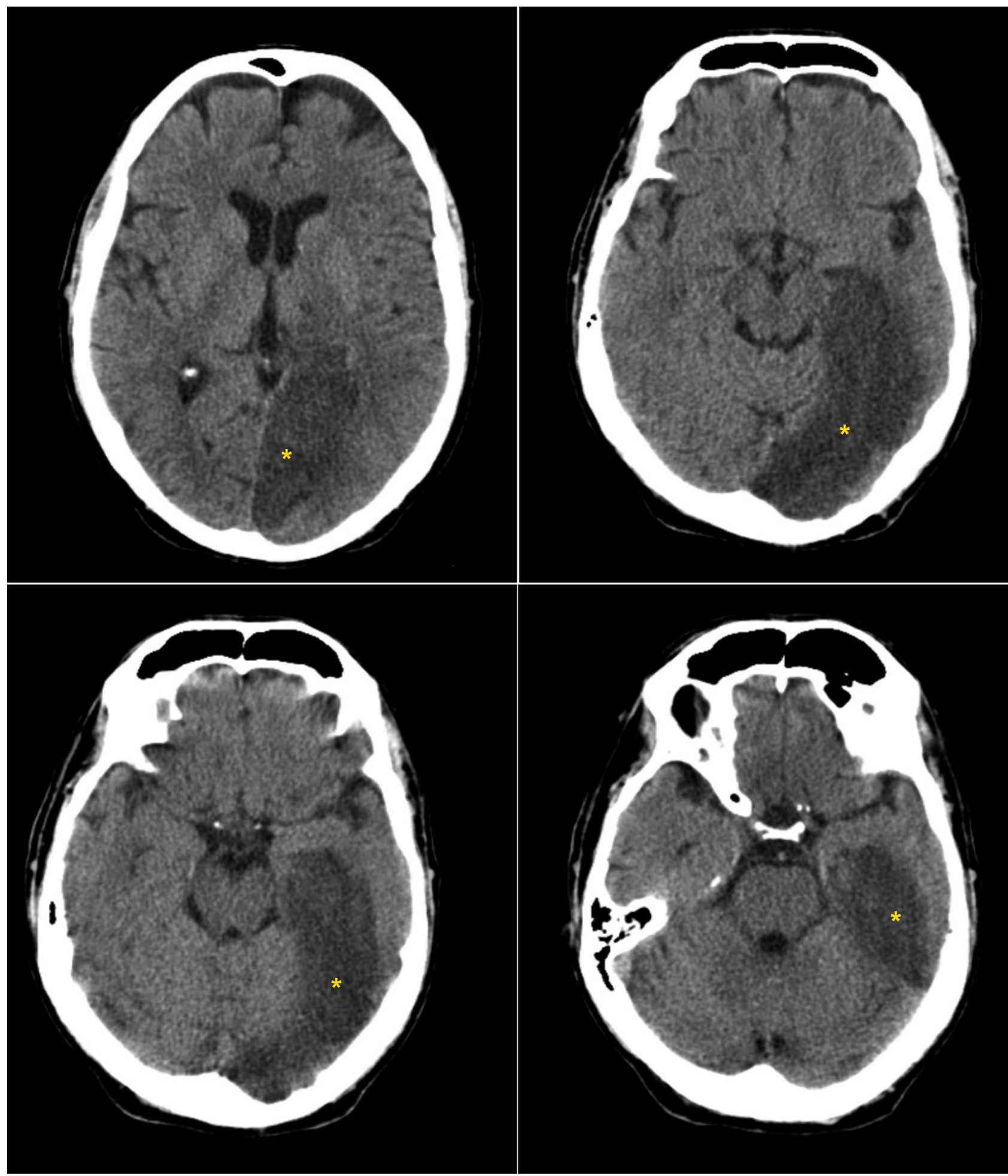

Figure 1 - Cranial CT showing ischemic injury in the territory of the left posterior cerebral artery (asterisc) 

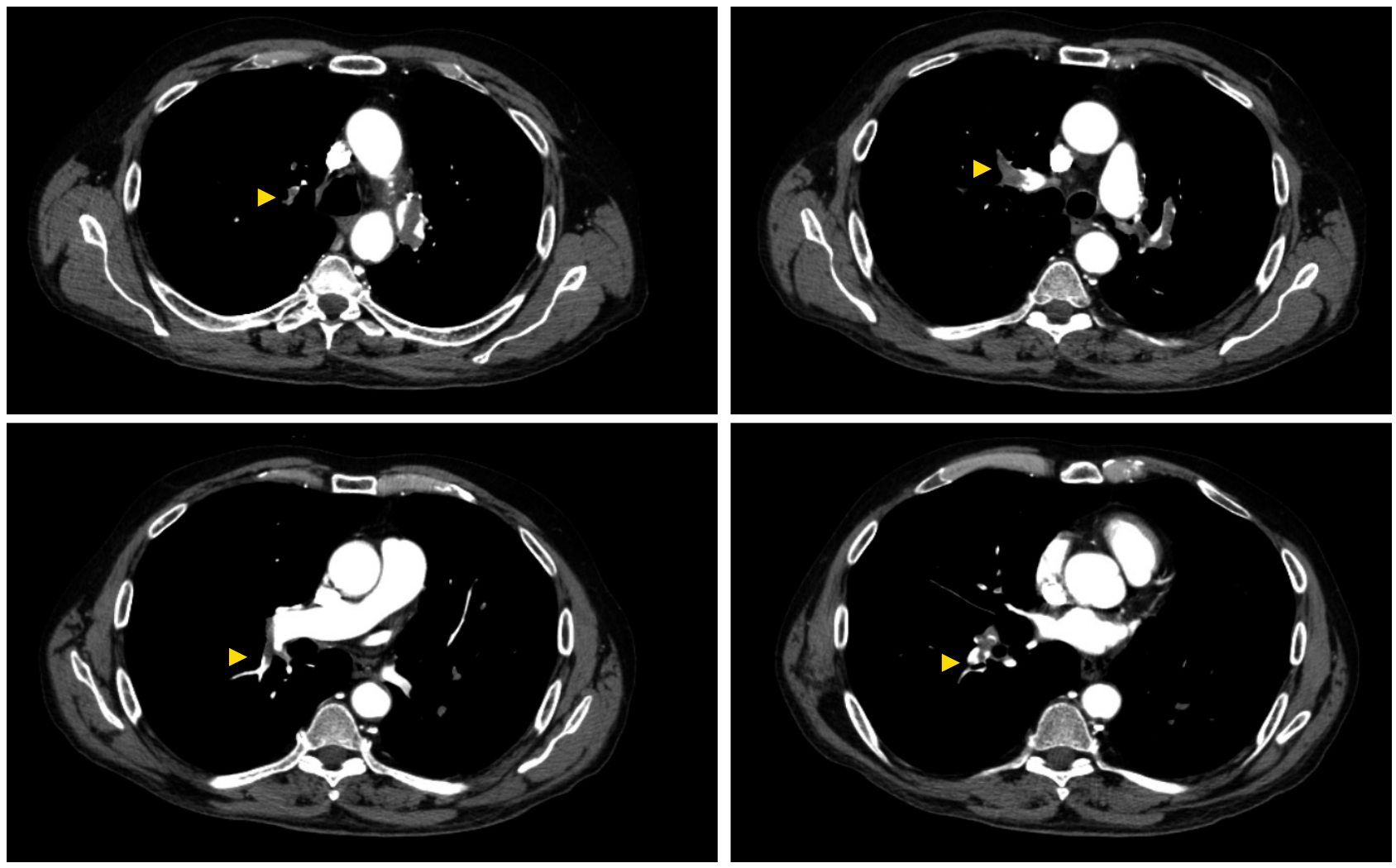

Figure 2 - CT pulmonary angiography showing massive pulmonary embolism (arrowhead)

cardiac laboratory biomarkers were negative.

The patient was hospitalized with the diagnoses of pulmonary embolism of intermediate-low risk (PESI class $\mathrm{V}$ and signs of right ventricular dysfunction), acute stroke and deep venous thrombosis.

At admission anticoagulation with low-molecular-weightheparin (LMWH) $1 \mathrm{mg} / \mathrm{kg}$ twice daily, along with antiplatelet therapy, was instituted. Due to the risk of cerebral hemorrhagic transformation, antiplatelet therapy was discontinued 72 hours after admission. Owing to a high suspicion of paradoxical embolism, contrast transesophageal echocardiography was performed which revealed the presence of a PFO with a small right-to-left shunt and no evidence of intra-cardiac masses or thrombi. Clinical improvement was observed throughout the hospitalization and the patient was discharged after 34 days of anticoagulation therapy. Percutaneous closure of the PFO was performed using an Amplatzer $^{\mathrm{TM}}$ PFO Occluder $25 \mathrm{~mm}$ device. The anticoagulant therapy was maintained indefinitely with full-dose LMWH. At the 6-month follow-up visit the patient remained in a rehabilitation program due to residual neurological sequelae (right homonymous hemianopsia and right hand astereognosis) and no recurrent embolic episodes were observed.

\section{DISCUSSION}

This case demonstrates the diagnostic steps and therapeutic approach in face of a patient with multiple thromboembolic events. The presence of several risk factors such as thrombophilia and lung cancer under chemotherapy treatment is likely to confer cumulative risk of venous throm- boembolism (VTE). ${ }^{3,4}$

The overlap of cryptogenic stroke with pulmonary embolism and deep vein thrombosis is very rare as initial presentation and a high level of suspicion must lead to an appropriate sequence of investigation and treatment. The contrast transesophageal echocardiography provides visualization of the PFO and can show the shunt itself, and the CT pulmonary angiography confirms the pulmonary embolism. ${ }^{2}$

For patients with both ischemic stroke and PFO with a venous source of embolism, anticoagulation is indicated. When anticoagulation is contraindicated, an inferior vena cava filter may be inserted. ${ }^{5,6}$ The type of anticoagulation treatment should be made on a case-by-case basis. Clinical guidelines recommend LMWH as first-line treatment of short- and long-term management of cancer-associated VTE. ${ }^{6-8}$ Vitamin $\mathrm{K}$ antagonists are considered second-line therapy with a higher recurrence rate but similar bleeding rates of around $5 \%$, when compared with $\mathrm{LMWH} .{ }^{9}$ Clinical data supporting the use of oral anticoagulants (NOACs) in cancer patients are recently available. Randomized trials have shown that rivaroxaban (for initial and long-term anticoagulation) and edoxaban (for long-term anticoagulation) are safe and effective. ${ }^{7}$ Those trials supported the American Society of Clinical Oncology guidelines on the use of NOACs for preventing and treating cancer associated VTE. Nevertheless, LMWH is preferred over NOACs in patients with increased risk of bleeding, or when drug interactions are suspected..$^{7,10}$

Moreover, the strategy regarding percutaneous transcatheter closure of PFO for secondary stroke prevention is 
still controversial. Randomized controlled trials have shown that PFO closure reduces stroke recurrence compared with medical therapy alone, ${ }^{11,12}$ but the evidence has been conflicting due to the differing roles that PFO can have in different scenarios. Currently, European societies have agreed on performing closure of a PFO in carefully selected patients aged from 18 to 65 years with confirmed cryptogenic stroke, transient ischemic attack or systemic embolism and an estimated high probability of a causal role of the PFO as assessed by clinical, anatomical and imaging features. ${ }^{13}$ In our case, we chose LMWH associated with percutaneous transcatheter closure of the PFO, since this was the first thromboembolic episode in an active cancer patient with high risk of recurrence and indefinite duration of medical therapy, associated with an increased risk of bleeding due to concomitant stroke.

\section{PROTECTION OF HUMANS AND ANIMALS}

The authors declare that the procedures were followed

\section{REFERENCES}

1. Sultan FA, Allen S, Sharif M, Mookadam F. Paradoxical thrombus 'caught in the act': Case report and review of the literature. Am J Med. 2017;130:23-5.

2. Naqvi SY, Sadiq A, Goldberg S. Recurrent paradoxical and pulmonary embolism, hypercoagulable state, and patent foramen ovale. Circulation. 2016;133:337-40.

3. Çinier G, Öz A, Tekkesin Al, Hayıroğlu MI, Keskin M, Avsar S. A young male patient with multiple thromboembolisms associated with factor $V$ Leiden mutation. Int Heart J. 2016;57:654-6.

4. Ikushima S, Ono R, Fukuda K, Sakayori M, Awano N, Kondo K. Trousseau's syndrome: cancer-associated thrombosis. Jpn J Clin Oncol. 2016;46:204-8.

5. Kernan W, Ovbiagele B, Black H, Bravata D, Chimowitz M, Ezekowitz M, et al. Guidelines for the prevention of stroke in patients with stroke and transient ischemic attack: a guideline for healthcare professionals from the American Heart Association/American Stroke Association. Stroke. 2014;45:2160-236.

6. Konstantinides S, Torbicki A, Agnelli G, Danchin N, Fitzmaurice D, Galiè $\mathrm{N}$, et al. ESC guidelines on the diagnosis and management of acute pulmonary embolism. Eur Heart J. 2014;35:3033-80.

7. Ay C, Beyer-Westendorf J, Pabinger I. Treatment of cancer-associated venous thrombo- embolism in the age of direct oral anticoagulants. Ann Oncol. 2019;30:897-907. according to the regulations established by the Clinical Research and Ethics Committee and to the Helsinki Declaration of the World Medical Association updated in 2013.

\section{DATA CONFIDENTIALITY}

The authors declare having followed the protocols in use at their working center regarding patients' data publication.

\section{PATIENT CONSENT \\ Obtained.}

\section{COMPETING INTERESTS}

All authors report no conflict of interest.

\section{FUNDING SOURCES}

This research did not receive any specific grant from funding agencies in the public, commercial, or not-for-profit sectors.

8. Lee A, Levine M, Baker R, Bowden C, Kakkar A, Prins M, et al. Lowmolecular-weight heparin vs. a coumarin for the prevention of recurrent venous thromboembolism in patients with cancer. $\mathrm{N}$ Engl $\mathrm{J}$ Med. 2003;349:146-53.

9. Louzada ML, Carrier M, Lazo-Langner A, Dao V, Kovacs MJ, Ramsay $\mathrm{T}$, et al. Development of a clinical prediction rule for risk stratification of recurrent venous thromboembolism in patients with cancer-associated venous thromboembolism. Circulation. 2012;126:448-54.

10. Key NS, Khorana AA, Kuderer NM, Bohlke K, Lee AY, Arcelus JI, et al. Venous thromboembolism prophylaxis and treatment in patients with cancer: ASCO Clinical Practice Guideline Update. J Clin Oncol. 2020;38:496-520.

11. Taggart N, Reeder G, Lennon R, Slusser J, Freund M, Cabalka A, et al. Long-term follow-up after PFO device closure: outcomes and complications in a single-center experience. Catheter Cardiovasc Interv. 2017;89:124-33.

12. Carroll J, Saver J, Thaler D, Smalling R, Berry S, MacDonald L, et al. Closure of patent foramen ovale versus medical therapy after cryptogenic stroke. N Engl J Med. 2013;368:1092-100.

13. Pristipino C, Sievert H, D'Ascenzo F, Mas JL, Meier B, Scacciatella P, et al. European position paper on the management of patients with patent foramen ovale. General approach and left circulation thromboembolism. Eur Heart J. 2019;40:3182-95. 